\title{
Policy Analysis on Identifying Copayment Services for the Shift in Financing Scheme of Health Care Services
}

\author{
Hilton Y. Lam, MHA, PhD, ${ }^{1,2}$ Ma-Ann M. Zarsuelo, RND, MSc, ${ }^{1,2}$ \\ Katrina Loren R. Rey, MD, ${ }^{1,2}$ Ma. Esmeralda C. Silva, MPAf, MSPPM, PhD, ${ }^{1,3}$ \\ Michael Antonio F. Mendoza, DDM, MA ${ }^{1,4}$ and Carmencita D. Padilla, MD, MAHPS \\ ${ }^{1}$ University of the Philippines Manila Health Policy Development Hub \\ ${ }^{2}$ Institute of Health Policy and Development Studies, National Institutes of Health, University of the Philippines Manila \\ ${ }^{3}$ College of Public Health, University of the Philippines Manila \\ ${ }^{4}$ College of Dentistry, University of the Philippines Manila \\ ${ }^{5}$ University of the Philippines Manila
}

\begin{abstract}
Background. As the Philippines moves toward universal health coverage, it is imperative to examine how to eliminate inefficiencies, particularly misuse, overutilization, and risks of fraudulent claims. This position statement aimed to identify health services requiring copayments for cost-efficient health financing for the Universal Health Care Act.

Methods. A qualitative study was employed using a systematic review of literature, and thematic analysis of policy roundtable discussion (RTD) was conducted. The systematic review of literature generated evidence for the policy brief and critical points for discussion in the stakeholders' RTD forum. The RTD was organized by the UP Manila Health Policy Development Hub (UPM HPDH) with the Department of Health (DOH) and was participated by key stakeholders of the policy issue to attain consensus recommendations and develop criteria for identifying services requiring copayments.
\end{abstract}

Results. An algorithm is proposed by the UPM HPDH based on collective expertise as a guide for policymakers to assess each benefit package in terms of overutilization, the danger of depleting government funds, and the risk of fraud. The use of clinical pathways is suggested to assess the misuse and overutilization of health services. In addition to copayments, benefits packages prone to fraudulent activities should be subjected to fraud prevention processes. Copayment should be linked inversely to the preventability level of the disease or condition.

Conclusion. There were gaps in the current policies to identify services requiring copayment services. Copayment schemes should be carefully determined to prevent misuse, overuse, and fraud of appropriate and necessary health services, while at the same time not limit access to needed care.

Key Words: copayment, cost-sharing, medical overuse, universal health insurance

\section{INTRODUCTION}

Total health expenditure is increasing globally over the past years. In 2016, 10.02\% of global GDP was used for health expenditures from $9.45 \%$ in $2011 .{ }^{1}$ In the Philippines, total health expenditure increased from $\mathrm{PhP} 737.8$ billion in 2017 to $\mathrm{PhP} 799.1$ billion in 2018 which represented an increase by $8.3 \%$. However, government spending remained low as a percentage of current health expenditure, with the

Corresponding author: Ma-Ann M. Zarsuelo, RND, MSc UP Manila Health Policy Development Hub National Institutes of Health University of the Philippines Manila 623 Pedro Gil St., Ermita, Manila 1000, Philippines Email:mmzarsuelo@up.edu.ph majority of expenditures for health being out-of-pocket (OOP). In 2018, OOP payment for health was at $53.9 \%$ compared to $34 \%$ of government health financing schemes. ${ }^{2}$

There are three categories of quality problems on health care that should be addressed as they contribute to total 
health expenditure. First is underuse, which is the insufficient provision of necessary care. Second is misuse, which is the provision of wrong care. Third is overuse, which is the provision of medical services at levels with no more benefit or for which harm outweighs the benefits. The problem with overuse is that it contributes to high health care costs. In the United States, some figures would estimate overuse to be up to $30 \% .^{3}$

Another problem in health care is fraud. The exact cost of fraud cannot be quantified because it can only be computed if fraud is reported or caught. However, the cost of fraud is inevitably high. ${ }^{4}$ In the Universal Health Care Act, a fraudulent act is defined as, "any act of misinterpretation or deception resulting in undue benefit or advantage on the part of the doer or any means that deviate from normal procedure and is undertaken for personal gain, resulting after that to damage and prejudice which may be capable of pecuniary estimation." 5

For an efficient healthcare system to work, improved patient care should be attained with minimized health care costs. These service quality problems can pose a risk to the patient and waste health resources; hence, reiterate the need to address them.

It has been suggested that generous insurance coverage can encourage patients to demand more testing and interventions than necessary. ${ }^{6,7}$ In response to increasing total health expenditure, many developed countries employ costsharing types: deductibles, copayment, and co-insurance. ${ }^{8}$ Deductibles is the amount to be paid at the initial period before insurance benefits apply. Copayment refers to the flat fee or pre-set amount paid at point-of-service, while co-insurance is the part of the medical bill paid for by the insured, with the remaining amount covered by the health insurance plan. ${ }^{5}$ Cost-sharing aims: (1) to reduce the demand of services to reduce moral hazards (when someone purposely increases exposure to risk while being insured); (2) to promote appropriate service utilization; and (3) to reduce third party payer expenditures. ${ }^{9,10}$ Cost-sharing mechanisms can also generate additional funds to improve health service quality and expand coverage of health services for increased accessibility. ${ }^{11}$ However, cost-sharing also carry risks, and the decision must be made on the appropriate amount. ${ }^{6}$ Evidence showed that when client cost-sharing is increased, even the use of appropriate health care services are minimized. ${ }^{11-15}$ Increased cost-sharing can hinder access to necessary care, which leads to poorer health outcomes. ${ }^{16}$ Thereby further increasing health care costs by preventing patients from seeking care earlier. $6,7,17$

When copayments are introduced or increased, utilization of preventive health care and curative services generally decreased. ${ }^{11}$ Even insurance plans with lower cost-sharing did not show increased utilization of health services. ${ }^{6,18}$ The problem of underuse of necessary health care due to costsharing is more pronounced among the marginalized and vulnerable populations. ${ }^{14,16}$ Placing copayments on outpatient consultations, for example, caused an increase in inpatient health care utilization. Furthermore, it has been suggested that patients who do not need hospitalization would prefer inpatient treatment to prevent repeated outpatient visits. ${ }^{19}$

Copayment can also lead to overpayment, as has been the case for medications. A study that compared reimbursements and copayments from pharmacy claims revealed that aggregate overpayments for medications reached a total of USD 135 million in 2013. Furthermore, 12 of the 20 most prescribed medications had overpayment rates of more than $33 \% .{ }^{20}$ Policymakers need to balance the rising pharmaceutical costs of medications and accessibility especially for the vulnerable population. ${ }^{21}$

Several strategies to regulate copayment mechanisms were noted in the literature review. A systematic review conducted by Lagarde et al. showed that although introduction or increasing fees for health service provision can hurt service utilization, there was evidence that when fees were introduced together with quality improvements, utilization of curative services increased. ${ }^{11}$

Copayment can be introduced for specialty care services with the rationale of "substitution effect,"whereby beneficiaries would decrease the use of more expensive specialty care in favor of less expensive primary care services. ${ }^{18}$ Meanwhile, uniform copayments should be discouraged because there is a difference in the clinical value of the service depending on the patient who receives it. It has been proposed that the amount of cost-sharing should be inversely related to the expected clinical benefits. This approach became known as value-based insurance design based on medical appropriateness (i.e., more valuable services are more accessible than services of lesser value). ${ }^{15}$

The concept of appropriateness modifier which was introduced by Song et al. (2018) would depend on correctness, suitability, and an indication for specific procedures. The indication may be based on the clinical presentation and patient characteristics. In terms of copayment, it can be decreased to promote appropriate services (e.g., immediate interventions for urgent situations) and increased for services that are less appropriate or not indicated (e.g., elective services without proven benefit compared to standard care). ${ }^{22}$ The utilization of the appropriateness modifier can be applied to services with established and observable indications and supported by guidelines. It is noted, however, that is limited by the small set of services available due to lack of supporting evidences. Also, the value of a service is in a continuum and not binary, and there might be a conflict in classifying highly appropriate and less appropriate services for each patient. Another challenge can be the tendency to "upcode" patients or change their diagnosis to make them fit highly appropriate situations. ${ }^{22}$

As the Philippines moves towards universal health coverage, we examine how to eliminate inefficiencies, particularly over-utilization and fraud, in claiming health benefits packages. The Department of Health (DOH) 
collaborated with UP Manila Health Policy Development Hub (UPM HDPH), as the research team, to gather inputs for the Implementing Rules and Regulations for the Universal Health Care Law. The DOH as the primary agency identified priority topics for the review of literature and multi-stakeholder discussion. The topic, Identifying Copayment Services, was a result of deliberation between the two parties, which aimed to answer the following questions: identify services requiring copayments, develop criteria for identifying services requiring copayments, and validate the list with relevant stakeholders.

\section{METHODS}

This study employed qualitative methods that utilized both systematic reviews of literature and a thematic analysis of policy roundtable discussion. Below is the flow of research inputs, from a review of literature to position statement.

\section{Research inputs for policy round table discussion}

A systematic review of literature was conducted through an electronic search of articles using PubMed and Cochrane. For PubMed, the keywords used were ("Cost Sharing"[Mesh] OR cost-sharing OR copayment) AND ("Medical Overuse"[Mesh] OR medical overuse OR overutilization)) OR (heath service misuse OR health fraud) which yielded 88 articles. Forty-eight articles were excluded after screening titles, and 28 articles were excluded after reviewing the abstracts. For Cochrane, the keywords "copayment OR cost-sharing AND medical overuse OR overutilization OR health service misuse" yielded 16 results. Thirteen articles were excluded after screening titles. Based on relevance, a total of 17 full-text articles were included in the review. A Google search using the above keywords was done to augment the reference list. An additional eight fulltext articles, five reports, and two laws from Official Gazette Philippines were included. Figure 1 shows the PRISMA diagram in the article search.

Results of the systematic review revealed that copayments could negatively affect the utilization of health care services, even when necessary, especially for the vulnerable population. Suggested strategies for copayment services included: (i) complementing copayment with improvements in health care delivery; (ii) introduction of copayment for specialty services to promote primary health care; (iii) discouragement of fixed copayment; and (iv) institution of value-based copayment schemes depending on medical appropriateness. Key findings from the literature review were presented in the roundtable discussion. For establishing background evidence on the policy issue, part of the literature review was utilized in the Introduction section of this paper.

\section{Conduct of the policy roundtable discussion}

A roundtable discussion (RTD) entitled, "Financing health services: Copayments and personnel cost were

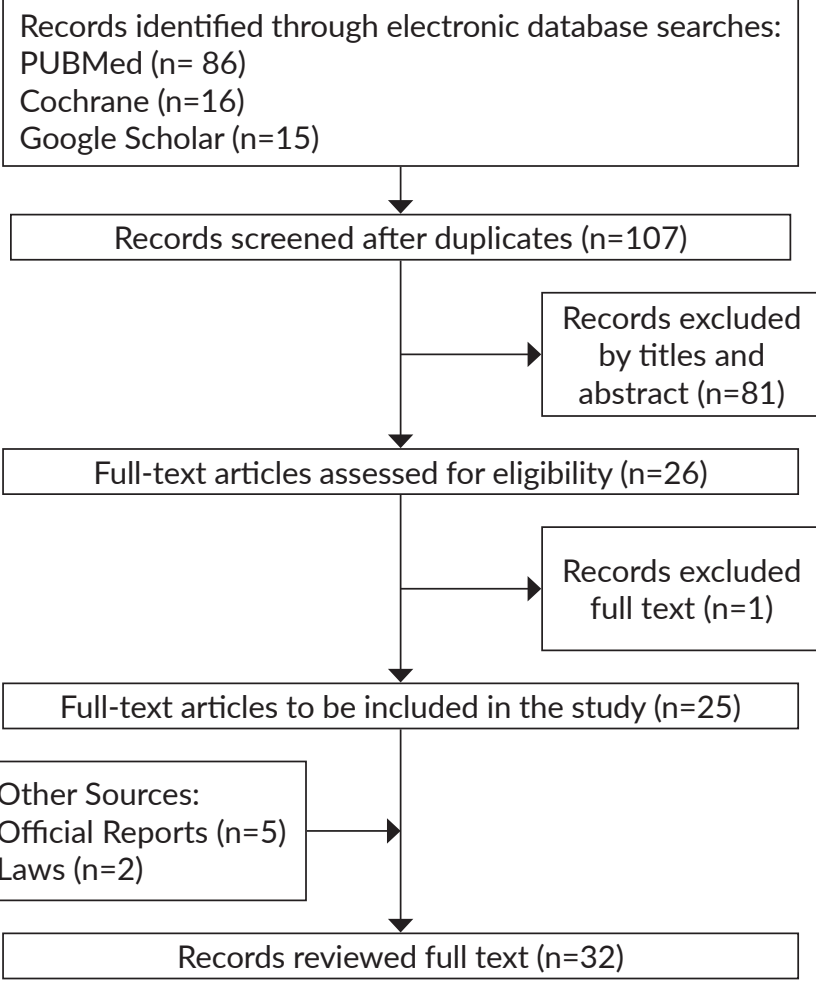

Figure 1. PRISMA Study Flow diagram.

conducted by the UP Manila Health Policy Development Hub (UPM HPDH) together with the Department of Health (DOH) on the Universal Health Care (UHC) Act, on 24 January 2019 at the Chancellor's Board Room, Philippine General Hospital. This will serve as input in crafting the Implementing Rules and Regulations (IRR) of the Law. The specific objectives drove discussion of the policy issue: to identify services requiring copayments in public health facilities, to develop criteria for identifying services requiring copayments, and to validate the list with relevant stakeholders.

Participants representing various agencies in the national and local government, private sector, hospital representatives, academe, professional societies, HMOs, and non-government and civil organizations shared their insights and ground knowledge on the policy issues for the development of consensus policy recommendations.

The UPM HPDH Chair presented the policy brief, highlighting the different types of cost-sharing and its useful features given as (i) to decrease moral hazard; (ii) to decrease behavioral hazard; and (iii) to decrease catastrophic risk and to encourage a healthier lifestyle. A proposed flowchart for identifying health services requiring copayments was presented for discussion. To provide background knowledge to all the participants, a representative from the Benefits Development and Research Department, PHIC, emphasized the need for costing exercises to identify rational copayment schemes. 
An algorithm was proposed by the UPM HPDH based on collective expertise as a guide for policymakers to decide on which services should have copayment (Figure 2). It was presented during the RTD and was subjected to review and assessment by the various stakeholders.

\section{Crafting of the Position Statement}

A thematic analysis of the RTD transcription was performed with discussion questions as sub-themes. In the instance that participant's input are mentioned in the paper, their identites were not disclosed to keep confidentiality. Further, all participants were informed that their names would be included in the publication in the form of an acknowledgment. To ensure consensus among all participants, the draft position statement was circulated back to them for inputs and approval, then reviewed by all the members of UPM HPDH before submitting to the UP Manila Chancellor for review, approval, and official endorsement to $\mathrm{DOH}$ and other relevant agencies. The review of literature was updated after the conduct of the RTD to include more recent studies.

\section{RESULTS AND DISCUSSION}

\section{Identifying Services Requiring Copayments}

\section{Services likely to be over-utilized in insurance / pre-} payment schemes

From the discussion, there was a consensus that currently, there are no precise and acceptable measurements for the overutilization of services in the Philippines. Overutilization is described as the delivery of services that are not beneficial or in which harm outweighs the benefits. A proposed mechanism is to compare the actual and expected rate of utilization for specific health services. However, this may be difficult due to the paucity of robust data on figures and prevalence. The issue of fraud was also raised as one of the critical factors in misused services.

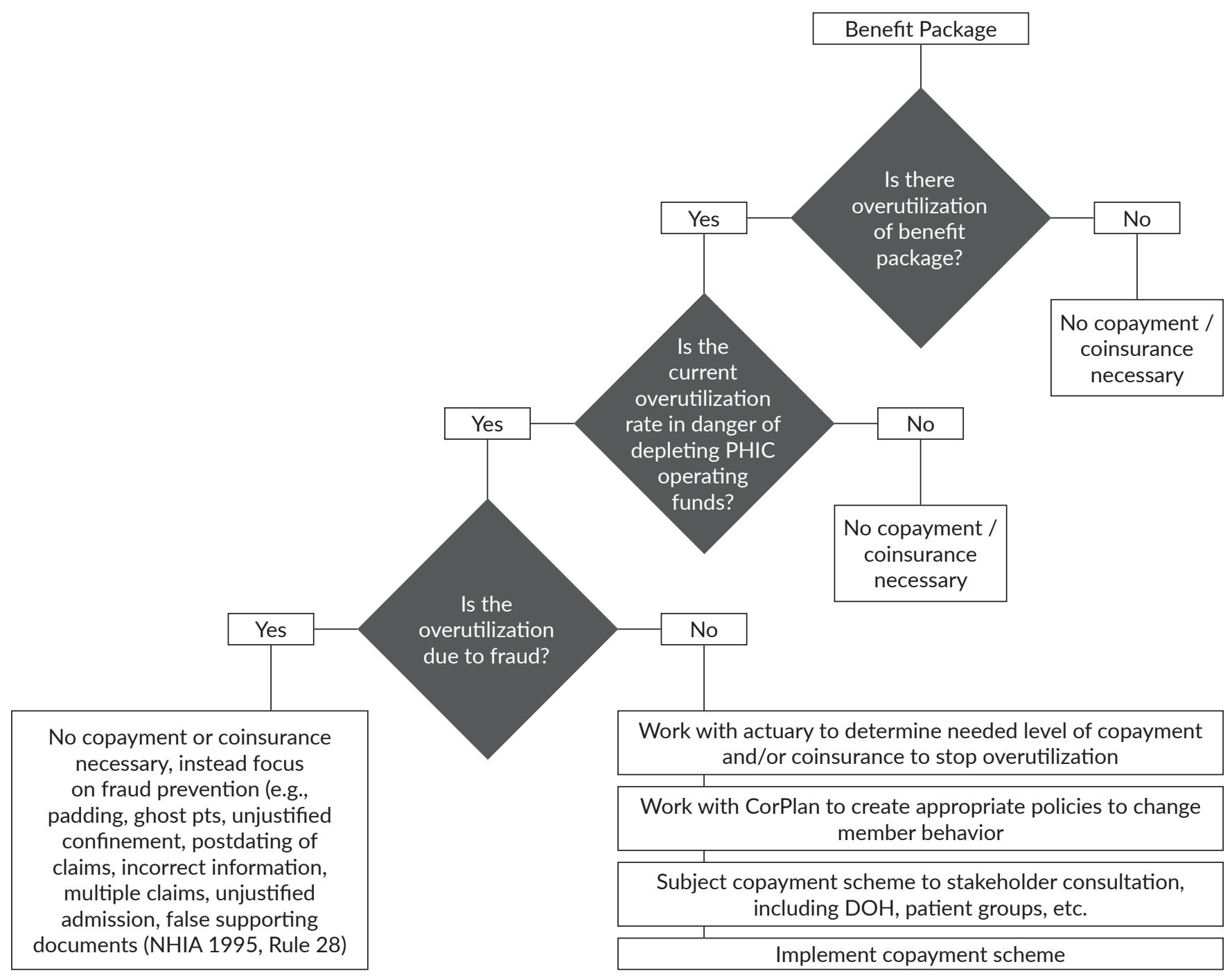

Figure 2. Proposed copayment flowchart. 
Cues to overutilization can be seen on itemized charges when performing manual evaluation of claims. Examples given in the discussion was the excessive claims for specific screening procedures (e.g., colonoscopy) and certain procedures that are reported as only a few minutes long. In some Level I hospitals, the number of admissions exceeded their bed capacities. There are patterns of cases that were admitted even though they are inadmissible. These red flags may be used as indicators for overutilization. However, one discussant raised that although it is good that these red flags can be identified, they also reflect a lack of guidelines and poor regulation. Hence, expanding the utilization of clinical pathways $(\mathrm{CP})$ could be considered.

Itemized hospital charges can examine service delivery, and when compared with protocols, they can help point to services that are consistent and inconsistent with protocols which can point to potential under- or overutilization of services, problems of inadequate documentation to provide the rationale for medical decisions and services and possible opportunities for health care education. ${ }^{23}$

Increasing requests for screening procedures like colonoscopy was argued as being justifiable and that it can be part of preventive screening for annual check-up. It was raised that the contribution of physicians in overutilization may be due to their efforts to please patients. Physicians can also practice "defensive medicine" wherein they order more tests than necessary to avoid litigation. ${ }^{6}$ Thereby, offering as many health services that will best guarantee the achievement of optimal health, may it be necessary or not. In the USA, the cost of "defensive medicine" ranges from USD 56 to 162 billion a year. ${ }^{24}$

PhilHealth is mandated to give financial protection for Filipinos with health-related risks. In an attempt to protect the vulnerable population, out-of-pocket payments are still reported to constitute $56 \%$ of total expenses. A representative from PhilHealth disclosed that the process of rationalizing the cost of PhilHealth reimbursement started in 2009 through collaborations of different sectors. The $\mathrm{DOH}$, along with counterparts in the European Union (EU), has been performing and validating costing exercises. In 2018, PhilHealth was determining unit costs of conditions, base rate, and diagnosis-related group (DRG) rate. Cost centers have been identified, to standardize data collection forms, equipment, furniture, fixtures, and specialty care to arrive at a cost that will maximize the DRG system. The process involved three phases given as Phase 1 - conducting training workshops; Phase 2 - developing online-based services; and Phase 3 - validation. Future directions involve capacity building, institutionalization, data submission, data collation, data validation, analysis of costing data, and unit cost as inputs to DRG for each package of PhilHealth. Once the costing framework is established, a pilot test will be conducted geared towards the end goal of having regular costing of health care services, and ultimately, lower out-ofpocket payments by members and beneficiaries.
Any procedure that deviates from PHIC approved clinical pathways can be deemed as possible misuse of services. According to Kinsman et al. (2010), clinical pathways are "tools used to guide evidence-based healthcare that has been implemented internationally since the 1980s." In fact, according to a 2015 United States Agency for Healthcare Research and Quality (AHRQ) report between 2010 and 2014, an estimated 87,000 fewer deaths and 2.1 million fewer cases from hospital-acquired infections occurred in the United States due mostly to "evidencebased tools" including clinical pathways, translating to an estimated savings of USD 19.8 billion.

However, the full potential of clinical pathways despite the creation of the American National Guidelines Clearinghouse, and despite the announcement that as of 2003, more than $83 \%$ of American hospitals already use clinical pathways, full adherence to clinical pathways by clinicians has not yet been achieved.

In a 2016 white paper, the Joint Commission International (JCI) identified the following issues leading to non-compliance to clinical pathways by clinicians: ${ }^{25}$

1. Lack of awareness about guidelines availability;

2. Lack of familiarity with guidelines;

3. Lack of agreement about guidelines;

4. Physicians focus on individual patterns, and many consider population-based clinical pathways of little help;

5. Physicians do not think they can comply with everything in the clinical pathways (i.e., time, cost, too many details, specified test, etc.);

6. Lack of success expectation;

7. Physicians lack incentives/ disincentives to change old habits; and

8. Confusion in the inter-use of terms (e.g., clinical pathways, clinical protocols, clinical practice guidelines), clinical bundle care map, and evidence-based care clinical algorithm.

According to a Rotter et al. (2010) review, there were 84 terms used interchangeably with clinical pathways, leading to confusion and fear of implementation. ${ }^{26}$ Roeder et al. (2003) elegantly make the case that "clinical pathways" should be the proper term. They further define clinical pathways as a "multidisciplinary plan of best clinical practices for a specified group of patients with a particular diagnosis that aid the coordination and delivery of highquality care. Clinical Pathways are utilized by a multidisciplinary team and focused on the quality and coordination of care." Thus, it is recommended that the proper term is "clinical pathway (CP)."

It was raised during a discussion that if the $\mathrm{DOH}$ (as authority body) and PHIC (as the accrediting body) will work together with the medical societies (as key experts and convene consultative process for $\mathrm{CPs}$ ), then clinical pathways for all the PHIC benefit packages can be created 
and would be pre-disposed to be accepted by Filipino physicians. By making adherence to $\mathrm{CPs}$ as a requirement for accreditation and payment of a reimbursement, the adherence of physicians may be further enticed. It is also recommended to allow limited authority in physicians' practice. The CPs will set the minimum expected standards (e.g., laboratory tests, imagery procedures, pre-conditions, medications including the use of National Formulary Drugs (NFDs), length of stay, etc.) so that PHIC can offer a reimbursement rate. If patients demand more, then patients will pay for just the additional procedures either from a reinsurance or out-ofpocket expenditure.

Ensuring that CPs are evidence-based and rigorously and critically appraised would lead to potential quality improvement of medical services in the UHC. Further, instituting a system of pre-authorization with the possibility of technical evaluation or professional visits (i.e., for high cost, high risk, or multiple procedures), not only recognizes the limitations of technology or healthcare professionals always accurately to diagnose diseases but also allows proactive quality management for potentially risky (financial or medically) procedures. Also, this pre-authorization-cumtechnical evaluation process may allow PHIC to redirect cases to under-utilized accredited facilities or redirect patients away from physicians whose skills in specific procedures are not ascertained.

\section{Local and international experiences/ interventions to reduce over-utilized services}

A study in the United States defined overuse as health service delivery that confers no benefit or for which harm outweighs the benefits. Defining overuse also requires the delineation of appropriate care. ${ }^{3}$ Examples of overused services include non-urgent consults at the emergency department, increased rates of low-risk cesarean delivery, and unnecessary imaging tests for assessment of abdominal pain in children. ${ }^{27}$ The problem with overuse is that it contributes to high healthcare costs. Unnecessary treatments constituted $34 \%$ of the total health care spending in the US. ${ }^{28}$ Addressing overuse will significantly reduce health care costs.

Purchasers must identify and quantify opportunities to minimize the misuse of health services. The Robert Wood Johnson Foundation identified a set of criteria that should be considered in prioritizing among the list of overused and misused services: (1) probable risk to patient-safety; (2) incidence and cost of a problem; (3) availability and completeness of data reporting on the scope of the problem; (4) degree of variation in practice; (5) depth of evidence on the magnitude of overuse; and (6) availability of established evidence-based clinical pathways. ${ }^{27}$

In California, a public deliberation was done among low to middle-income citizens to identify the best strategies to address overuse in medical care. The majority of participants reported that physician leaders should be responsible for addressing the problem of overuse in health care. Physicians must institute corrective measures among fellow physicians. They opposed the option of monetary incentives to reduce overuse, and this option was viewed as contradictory to medical professionalism. Twenty-six percent (26\%) supported higher cost-sharing for unnecessary interventions. Participants viewed it as advocating for patient's choice to receive interventions they prefer despite the higher cost. However, some viewed this as unethical for physicians to agree to give patients unwarranted or possibly harmful services regardless of who paid for it. ${ }^{29}$

Continuity of patient care may also play in reducing the overuse and misuse of health services. This is attributed to trust and familiarity between the patient and the provider. Efforts to promote primary care delivery with priority on continuity of care may play a role in reducing health care costs. ${ }^{6}$

To avoid litigation, a proposed reform to address the practice of defensive medicine would be to ensure that physicians who adhere to guidelines and standards of care would be protected from lawsuits. ${ }^{17}$

In the Philippines, the overutilization of services is regulated under the provisions of Section 47 of Revised Implementing Rules and Regulation of the National Health Insurance Act of 2013. Health care providers will be penalized for claims under circumstances of "over-utilization of services, unnecessary diagnostic and therapeutic procedures and interventions, irrational medication prescriptions, fraudulent, false or incorrect information, gross unjustifiable deviations from the accepted standard of practice or treatment protocols, inappropriate referral practices, use of fake, adulterated or misbranded pharmaceuticals or unregistered drugs, use of drugs other than those recognized in the latest Philippine National Formulary ... and failure to comply without justifiable cause with pertinent provisions of law." ${ }^{30}$ Issues of fraud in the past have also hounded the National Health Insurance Program (NHIP). The Philippine Senate launched a probe on an estimated $\mathrm{PhP} 2$ billion believed to have been lost by PhilHealth due to fraudulent claims last 2015. ${ }^{31}$ The Commission on Audit also reported last 2014 that PhilHealth billed DOH the amount of PhP 35.293 billion for insurance premiums of 14,706,524 indigent families. However, only 9,546,439 families were enrolled. ${ }^{32}$ With the Universal Health Care Act, enforcing these regulations to minimize over-utilized and fraudulent claims will significantly impact on the financial sustainability of the NHIP.

\section{Criteria in identifying services requiring copayments}

As a guide for policymakers to decide on which services should have copayment, an algorithm was crafted by UPM $\mathrm{HDPH}$, as shown in Figure 2. Each benefit package will be assessed using the following questions: (1) Is there overutilization of the benefits package?; (b) Is the current utilization rate in danger of depleting PHIC operating funds?; and (c) Is the overutilization due to fraud? Benefits packages 
that are not overutilized and will not endanger operating funds allocated for that package will not need copayment or coinsurance. Meanwhile, benefits packages that are judged to be overutilized will have a rational cost-sharing mechanism coupled with policy amendments aimed at altering the behavior of members and stakeholder consultations with significant partners such as $\mathrm{DOH}$, patient groups, among others. Assessment of over-utilization will be through the application of clinical pathways (CPs) that are developed by the medical societies, or the Department of Health, and approved by PhilHealth. For every PHIC benefit package, one clinical pathway must be approved and disseminated to all accredited providers. Over-utilized benefit packages prone to fraudulent activities will have no cost-sharing activities and will have fraud prevention systems in place instead. The success of the algorithm depends on a robust monitoring and evaluation system that will allow the PHIC to identify what packages are being over-utilized and more prone to fraud. Coordination with the budget and planning system is needed to know if the package can potentially deplete funds allocated for it. Lastly, there should be a set of indicators to raise the red flags for fraudulent claims.

During the discussion, relevant provisions from the UHC Act for copayment and coinsurance were tackled, which included Section 9,16a, 16b, 18a, 18b, and 41e. The following were raised and clarified by the RTD participants.

The Health Maintenance Organization (HMO) set-up, jointly acting as the last peso insurance, was assessed. Under HMOs, a plan holder receives an annual maximum benefit limit (MBL) per illness/ injury of Aggregate Benefit Limit (ABL). This depends on premiums paid based on several factors, particularly the client's age, and occupational risks. Every HMO aims to prevent over-utilization of program benefits through adherence to established Clinical Pathways and promotion of a rational, ethical, and evidence-based use of diagnostics, treatments, and medicines. Nevertheless, these are primarily dependent on their accredited doctors. However, unlike social insurance, most HMOs still do not have senior citizen packages.

In other countries, health coverage has a broader scope because they have higher taxes. PhilHealth has the lowest premium in Asia, and it is an insurance that is premiumbased compared to other countries which are tax-based. Other countries have sufficient taxes to cover their entire health service. The estimated $\mathrm{PhP} 408.6$ billion over a four year period by the World Bank may compromise PhilHealth's financial sustainability in the future.

The unique features of PhilHealth as a social insurance were also elaborated. Unlike the insurance from the rest of the world, PhilHealth is an insurance of the first peso with a support value of only 33\%. Nevertheless, it also functions as an insurance of the last peso for recipients of the 'no balance billing.'

Moving towards the universal health care, funds appropriation (Section 37) to implement the Act will be sourced from Sin Tax Reform, 50\% of the government share of Philippine Amusement and Gaming Corporation (PAGCOR) income, and $40 \%$ of charity funds including Philippine Charity Sweepstakes Office (PCSO). A representative from $\mathrm{PCSO}$ mentioned that along the pipeline is the $\mathrm{PhP} 5$ billion remittances of the agency to PhilHealth as a source of additional funds. However, even with an increase in the national health insurance budget, covering up to the last peso remains a challenge. With the UHC Act transitory provision of the city- and province-wide financial integration, it is the goal of PhilHealth to timely determine the copayment and coverage of health services.

In general, higher copayment leads to lower access to health services; hence both copay and co-insurance should not exceed $30 \%$ of the annual income of the client. Therein, the clinical pathways $(\mathrm{CP})$ would help determine appropriate diagnostics and treatment for every patient. There might need to have continuous updating of $\mathrm{CP}$, engaging various medical societies, which could subsequently lead towards more cost-efficient health service financing. There should be evidence-based treatment plans for specific diseases that could also be anchored towards disease prevention and health promotion. In monitoring and evaluation, it was proposed that disincentives can be applied to violators of the proposed guidelines.

In essence, only no-balance billing (NBB) benefit packages (e.g., for indigent patients in government hospitals who are protected under zero out-of-pocket guarantee) should be subject to copayments as these are insurance of the last peso. Even within this subgroup, preventive services should not be subject to copayments, nor should end of care or palliative care services, as these tend to be not sizeable in total peso value. One participant raised that copayment should be linked inversely to its preventability nature. For example, if a condition is not preventable (e.g., arthritis, appendicitis, etc.), then copayment should be as small as possible, even zero. However, if the condition is preventable (e.g., measles or other vaccine-preventable diseases), then the copayment can be high, depending on the actuarial study of PHIC.

This was supported by the model of the Affordable Care Act (ACA) in the USA, which covers preventive services at no cost-sharing. This can be similarly adopted for other services (e.g., chronic care) wherein a list of services can be compiled to manage a chronic disease that is proven to be effective and for which the cost of care restricts utilization. ${ }^{17}$

On another note, one of the participants pointed out that the role of allied medical professionals and dentists should also be recognized in the implementation of the Universal Health Care Law.

\section{Collection of relevant data to finalize services requiring copayments}

Based on the challenges noted and recommendations raised from the review of literature, proposed algorithm, and policy discussion, PhilHealth should ensure the creation 
and acceptance of clinical pathways for all its benefit packages. PhilHealth should identify the list of services requiring copayments, working with its actuary. This should then be subjected to consultations with the Department of Health and other relevant sectors.

\section{Validation of list of services requiring copayments}

The list of proposed services analyzed by PhilHealth should be subjected to meetings conducted by the Department of Health, wherein different key stakeholders must be consulted before finalization. This will pro-actively prevent possible policy issues and gaps in the implementation. Further, it will yield more robust inter-sector participation and support during implementation.

\section{CONCLUSION AND RECOMMENDATIONS}

There are gaps in the current policies to identify services requiring copayments. Copayment schemes should be carefully determined to prevent misuse, overuse, and fraud of appropriate and necessary health services, while at the same time not limit access to needed care. The list of services requiring copayment services should be reviewed by relevant stakeholders and sectors to ensure support during implementation.

Based on the review of literature and policy discussion, the following was recommended:

1. Clinical Pathways $(\mathrm{CP})$ would help determine appropriate diagnostics and treatment for every patient. They should be used to identify and prevent overutilization of health services. Various medical societies should be engaged to develop and update CPs to lead to a more cost-efficient health service financing and higher quality of care.

2. Evidence-based treatment plans can be developed for specific diseases, which could also be anchored towards disease prevention and health promotion. In monitoring and evaluation, disincentives can be applied to violators of the proposed guidelines, and copayments may be applied only to interventions of diseases that are preventable. Copayments should not be considered for preventive services, for end of life services, nor for first peso covered services.

3. Fraud prevention and prosecution must be strictly applied.

\section{Statement of Authorship}

All authors participated in data collection and analysis, and approved the final version submitted.

\section{Author Disclosure}

All authors declare no conflicts of interest.

\section{Funding Source} HPSR.

\section{REFERENCES}

1. The World Bank. Current health expenditure (\% of GDP) [Internet]. 2019 [cited 2019 Dec 10]. Available from: https://data.worldbank. org/indicator/SH.XPD.CHEX.GD.ZS? end $=2016 \&$ start $=2000 \&$ view=chart.

2. Philippine Statistics Authority. Total Health Expenditures grew by 8.3 percent in 2018. [Internet]. 2019 [cited 2019 Dec 10]. Available from: https://psa.gov.ph/pnha-press-release.

3. Korenstein D, Falk R, Howell EA, Bishop T, Keyhani S. Overuse of health care services in the United States: an understudied Problem. Arch Intern Med. 2012 Jan; 172(2):171-8. doi: 10.1001/ archinternmed.2011.772.

4. Hoffer EP. America's Health Care System is Broken: What Went Wrong and How We Can Fix It. Part 5: Malpractice, Fraud, Waste, and the EMR. Am J Med. 2019 Oct; 132(10):1129-32. doi: 10.1016/ j.amjmed.2019.05.009.

5. Republic Act 11223. An act instituting Universal Health Care for All Filipinos, Prescribing Reforms In the Health Care System, Amending For The Purpose Certain Laws, Appropriating Funds Therefor. 17th Congress, 3rd Session. 2019.

6. Rosenthal MB, Colla CH, Morden NE, Sequist TD, Mainor AJ, Li $Z$, et al. Overuse and insurance plan type in a privately insured population. Am J Manag Care. 2018 Mar; 24(3):140-6.

7. Newhouse JP, Manning WG, Morris CN, Orr LL, Duan N, Keeler $\mathrm{EB}$, et al. Some interim results from a controlled trial of cost sharing in health insurance. N Engl J Med. 1981 Dec; 305(25):1501-7. doi: 10.1056/NEJM198112173052504.

8. Small Business Majority. Cost-sharing. [Internet]. 2018 [cited 2018 Dec 18]. Available from: https://healthcoverageguide.org/referenceguide/benefits-providers-and-costs/cost-sharing/.

9. Luiza VL, Chaves, LA, Silva RM, Emmerick ICM, Chaves GC, Fonseca de Araújo SC, et al. Pharmaceutical policies: effects of cap and co-payment on rational use of medicines. Cochrane Database Syst Rev. 2015 May; 2015(5):CD007017. doi: 10.1002/14651858. CD007017.pub2.

10. Hossein Z, Gerard A. Trends in cost sharing among selected high income countries 2000-2010. Health Policy. 2013 Sep; 112(1-2): 35-44. doi: 10.1016/j.healthpol.2013.05.020.

11. Lagarde M, Palmer N. The impact of user fees on access to health services in low- and middle-income countries. Cochrane Database Syst Rev. 2011 Apr; (4):CD009094. doi: 10.1002/14651858.CD009094.

12. Agarwal R, Gupta A, Fendrick AM. Value-based insurance design improves medication adherence without an increase in total health care spending. Health Aff (Milwood). 2018 Jul; 37(7):1057-64. doi: 10.1377/hlthaff.2017.1633.

13. Volpp KG, Loewenstein G, Asch DA. Choosing wisely: low value services, utilization, and patient cost sharing. JAMA. 2012 Oct; 308(16):1635-6. doi:10.1001/jama.2012.13616.

14. Vardy DA, Freud T, Shvartzman P, Sherf M, Spilberg O, Goldfarb $\mathrm{D}$, et al. Introducing co-payment for consultant specialist services. Isr Med Assoc J. 2006 Aug; 8(8):558-62.

15. Kelly AM, Cronin P, Carlos RC. Introduction to value-based insurance design. J Am Coll Radiol. 2008 Nov; 5(11):1118-24. doi: 10.1016/ j.jacr.2008.06.014.

16. Geyman JP. Moral hazard and consumer-driven health care: a fundamentally flawed concept. Int J Health Serv. 2007; 37(2):333-51. doi: 10.2190/J354-150M-NG76-7340.

17. Cutler DM. From the Affordable Care Act to Affordable Care. JAMA. 2015 Jul; 314(4):337-8. doi: 10.1001/jama.2015.7683.

18. Shah ND, Naessens JM, Wood DL, Stroebel RJ, Litchy W, Wagie A, et al. Mayo Clinic employees responded to new requirements for cost sharing by reducing possibly unneeded health services use. Health Aff (Millwood). 2011 Nov; 30(11):2134-41. doi: 10.1377/ hlthaff.2010.0348.

19. Yoo KB, Ahn HU, Park EC, Kim TH, Kim SJ, Kwon JA, et al. Impact of co-payment for outpatient utilization among Medical Aid beneficiaries in Korea: A 5-year time series study. Health Policy. 2016 Aug;120(8):960-6. doi: 10.1016/j.healthpol.2016.07.001. 
20. Van Nuys K, Joyce G, Ribero R, Goldman DP. Frequency and Magnitude of Co-payments Exceeding Prescription Drug Costs. JAMA. 2018 Mar; 319(10),1045-7. doi: 10.1001/jama.2018.0102.

21. Green CJ, Maclure M, Fortin PM, Ramsay CR, Aaserud M, Bardal S. Pharmaceutical policies: effects of restrictions on reimbursement. Cochrane Database Syst Rev. 2010 Aug; 2010(8):CD008654. doi: 10.1002/14651858.CD008654.

22. Song Z, Navathe AS, Emanuel EJ, Volpp KG. Incorporating value into physician payment and patient cost sharing. Am J Manag Care. 2018 Mar; 24(3):126-8.

23. Terra SM. What can claims data tell the case manager? Prof Case Manag. 2008 Jul-Aug; 13(4):195-208; quiz 209-10. doi: 10.1097/01.PCAMA.0000327408.71354.52.

24. Berlin L. Medical errors, malpractice and defensive medicine: an illfated triad. Diagnosis (Berl). 2017 Sep; 4(3):133-9. doi: 10.1515/ $\mathrm{dx}-2017-0007$.

25. Joint Commission International. Clinical Practice Guidelines: Closing the Gap Between Theory and Practice. USA: Joint Commission International, 2016.

26. Rotter T, Kinsman L, James E, Machotta A, Gothe H, Willis J, et al. Clinical pathways: effects on professional practice, patient outcomes, length of stay and hospital costs. Cochrane Database Syst Rev. 2010 Mar; (3):CD006632.

27. Burns M, Dyer MB, Bailit M. Reducing Overuse and Misuse: State Strategies to improve quality and cost of health care. State Health and Value Strategies. Robert Wood Johnson Foundation [Internet]. 2014 Jan [cited 2018 Dec 20]. Available from: https://www.rwjf.org/ en/library/research/2014/01/reducing-overuse-and-misuse-statestrategies-toimprove-quality.html.
28. Berwick DM, Hackbarth AD. Eliminating waste in US health care. JAMA. 2012 Apr; 307(14):1513-6

29. Perez SL, Backman D, Ginsburg M. Assessing social values for California's efforts to reduce the overuse of unnecessary medical care. Health Expect. 2018 Apr; 21(2),501-7.

30. PhilHealth. The revised implementing rules and regulations of the National Health Insurance Act of 2013 (RA 7875 as amended by RA 9241 and 10606); 2013.

31. Rappler.com. Senate to probe questionable PhilHealth claims. Philippines: Rappler.com [Internet]. 25 Jun 2015 [cited 2019 Jan 10]. Available from: https://www.rappler.com/nation/97446-senate-probequestionable-philhealth-claims.

32. Congressional Policy and Budget Research Department House of Representatives. CPBRD Policy Brief No. 2016-09: Financial Sustainability of the National Health Insurance Program: A Review of the Actuarial Valuation Report 2014 of PhilHealth. [Internet]. 2014 [cited 2019 Jan 10]. Available from: http://cpbrd.congress.gov. ph/images/PDF\%20Attachments/CPBRD\%20Policy\%20Brief/ PB2016-09_Valuation_Report_2014_of_Philhealth.pdf. 